\title{
Analysis on A Case of Marine Hydraulic Steering Gear Failure
}

\author{
Xiaohua Ye \\ Qingdao Ocean Shipping Mariners College, Qingdao Shandong 266071, CHINA \\ email, yexhqmc@126.com
}

Key Words: hydraulic steering gear, auxiliary machinery, steering mechanism, rudder blade Abstract: The hydraulic steering gear is an important equipment of the ship and its failure could contribute to navigation unsafely. With regard to the failure of a certain hydraulic steering gear and inspection of the steering mechanism, this article specifies reasons for the failure of the steering gear and puts forward methods including control to the design, selection and manufacture and enhancement to the watch-keeping and ship-repairing so that the similar accidents could be avoided. In this case, the analysis and treatment to the failure of the marine hydraulic steering gear could result in the prevention and elimination to the failure.

\section{Introduction}

The marine hydraulic steering gear is an important equipment to control the course. Once a failure occurs and could not be eliminated in time, the course would not be controlled and the navigation safety of the ship could also be affected. The failure of steering gear involves various aspects such as the design, use and maintenance, which requires a thorough analysis. ${ }^{[1-3]}$ According to the failure of the steering gear of an ocean-going ship, the failure of the steering gear is investigated in various aspects.

\section{Overview to the Failure}

The ship is a double-bottom ocean-going oil tanker. The main parameters of the ship are as follows:

Table 1 Main Parameters of the Ship

\begin{tabular}{|l|l|l|l|l|l|}
\hline Name & Parameter & Name & Parameter & Name & Parameter \\
\hline $\begin{array}{l}\text { Length } \\
\text { Overall }\end{array}$ & $101.9 \mathrm{~m}$ & $\begin{array}{l}\text { Gross } \\
\text { Tonnage }\end{array}$ & $3726 \mathrm{t}$ & Load & $4881.27 \mathrm{t}$ \\
\hline $\begin{array}{l}\text { Moulded } \\
\text { Depth }\end{array}$ & $16.0 \mathrm{~m}$ & Net Tonnage & $1251 \mathrm{t}$ & Speed & $12.0 \mathrm{~m} / \mathrm{h}$ \\
\hline $\begin{array}{l}\text { Moulded } \\
\text { Breadth }\end{array}$ & $8.0 \mathrm{~m}$ & $\begin{array}{l}\text { Summer } \\
\text { Waterline }\end{array}$ & $5.9 \mathrm{~m}$ & Rudder & $\begin{array}{l}\text { Spade } \\
\text { Rudder }\end{array}$ \\
\hline
\end{tabular}

This ship sailed from Singapore to China. The steering gear was tested and corrected one hour before sailing. It took 14 seconds from one side $30^{\circ}$ to the other side $35^{\circ}$. And it was normal. After a few days, an autopilot yaw alarm suddenly rang. The OOW confirmed the autopilot and the ship's heading immediately and found that the bow shifted to the right. The rudder was switched to manual position and the ship still yawed promptly. Turning to the emergency rudder, it didn't answer to the port and starboard rudder. The master ordered to slow down and stop the main engine and showed not under command light as well as deck light; besides, we broadcasted to other ships in the vicinity with VHF16 and set AIS to the out of control state; meanwhile, we reported to the company's emergency response center. The ship is in a drifting state due to rudder failure.

\section{Failure Analysis}

\section{Troubleshooting}

The failure of the steering gear is mainly due to failure of electrical and hydraulic system, steering mechanism and rudder blade. ${ }^{[4]}$ The hydraulic system of this ship is shown in Figure 1. 
The system is a pump-controlled closed hydraulic system, which consists of two sets of main pumps, pipe systems and two pairs of working cylinders. During the voyage, the two main pumps

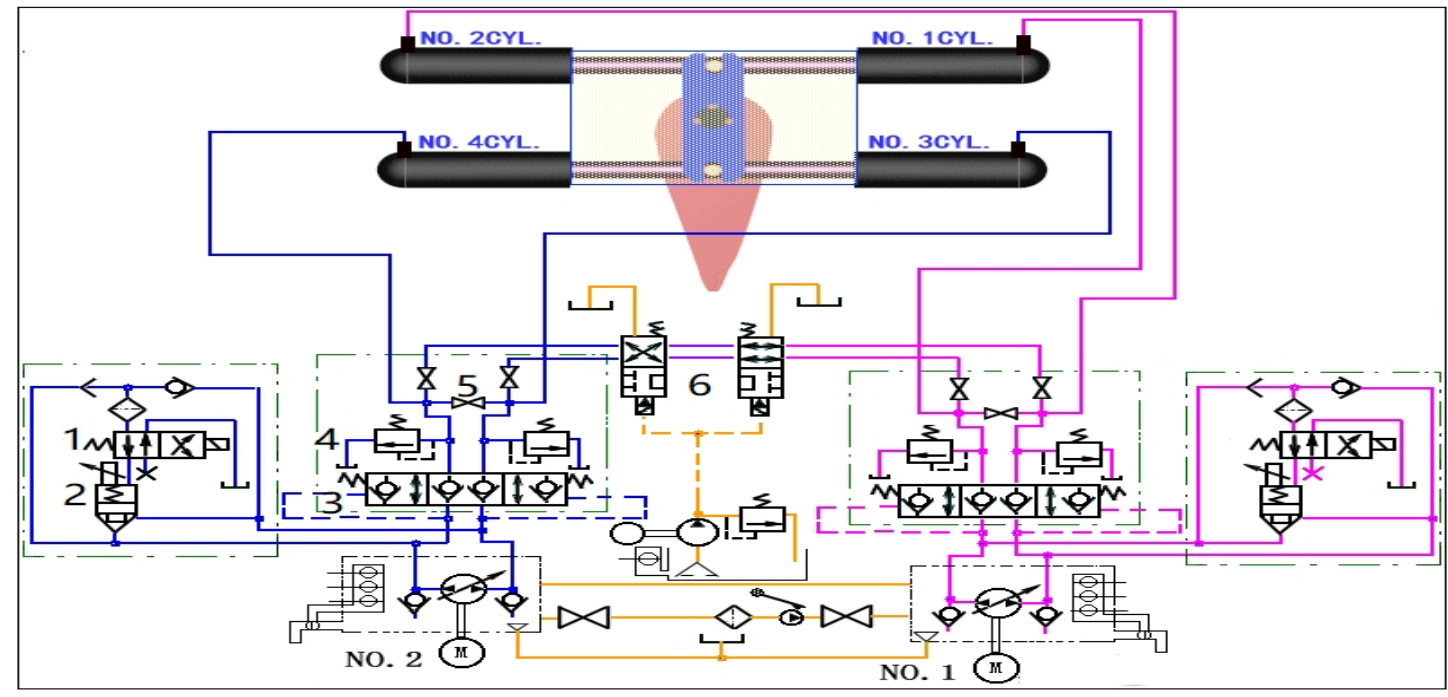

Fig.1 Hydraulic System of Steering Gear

are used as the standby pump for each other to improve the reliability of the equipment. The main hydraulic components of the main circuit are as follows. (1) Unloading valve. It consists of two-position two-way solenoid divert valve 1 and logic valve 2 . When starting, the main pump unloads and starts. After startup is accomplished, the solenoid valve makes the system load and work normally. (2) Kawasaki-style special-purpose valve. It is mainly composed of a lock valve 3 on the fuel manifold, a pair of storm valves 4, and a bypass valve 5. The lock valve 3 on the fuel manifold can prevent rudder angle from being out of control, the storm valve 4 can play a role in two-way security, and the bypass valve 5 can functions to select working conditions of the steering gear. (3) Automatic isolating valve 6. When the oil level of the certain tank is too low, the main pump stops running while the isolating valve is energized, and the corresponding cylinder is bypassed. ${ }^{[5]}$

According to the above analysis of the hydraulic system, the reasons why the steering gear cannot rotate effectively may be as follows:

(1) Unloading valve fails and logic valve 2 still opens so that hydraulic oil flows directly back to the tank instead of to the working cylinder.

(2) Storm valve still opens which results in hydraulic fluid flows back to the tank. In that case, the oil pressure is insufficient to drive the steering mechanism.

(3) Failure of the main or auxiliary oil pump results in insufficient oil pressure to drive the steering gear.

(4) Leakage of the cylinder is seriously so that the oil pressure could not be built up.

With regard to the above analysis, the chief engineer checks the working conditions of the steering gear hydraulic system in the steering gear room after the failure. He finds that the hydraulic system functions normally and the steering gear operates normally as well. As a result, electrical faults and hydraulic system failures can be eliminated, and the underwater part of the steering mechanism should be taken into account.

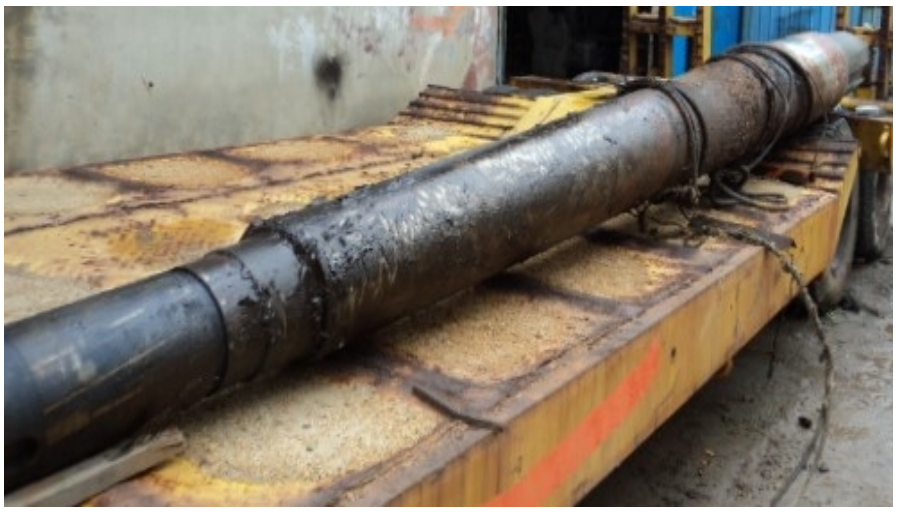

Fig. 2 Rudder Stock 


\section{Inspection to Underwater Part of Steering Gear}

The underwater part of the steering gear is inspected and the rudder blade of the steering gear found lost. The ship immediately proceeds to the shipyard for repair and makes further inspection to the underwater part which is as follows:

(1) Inspection to the rudder stock: The length overall of the rudder stock is $5925 \mathrm{~mm}$, diameter $430 \mathrm{~mm}$, and the surface is in good condition. There is no wear, strain or deformation. The keyway is approximately normal, which is shown in Figure 2.

(2) Inspection to the fixed parts of the rudder stock: The tightening nut on the rudder blade is M260*6 and the height is $210 \mathrm{~mm}$. No tightening nut is found during the inspection; the crest of the screw part of the rudder stock is damaged, and the bottom of the rudder stock is flat. As shown in Figure 3 and Figure 4.

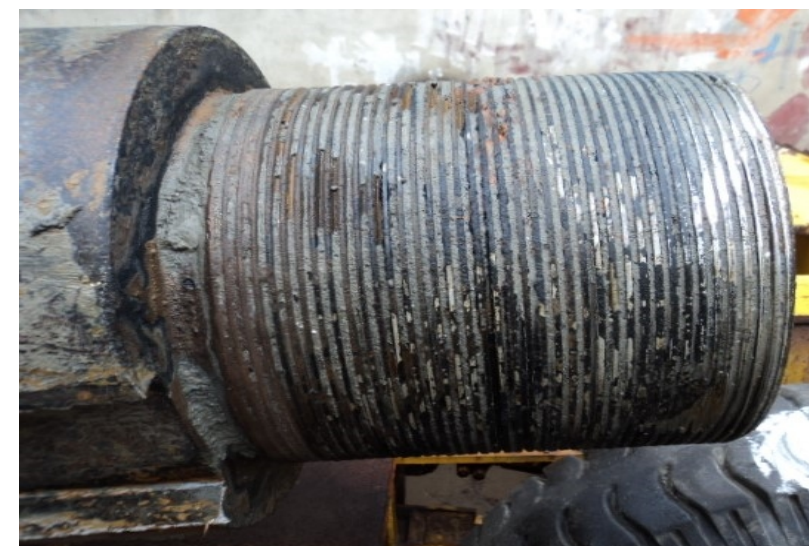

Fig.3 Rudder Stock Screw

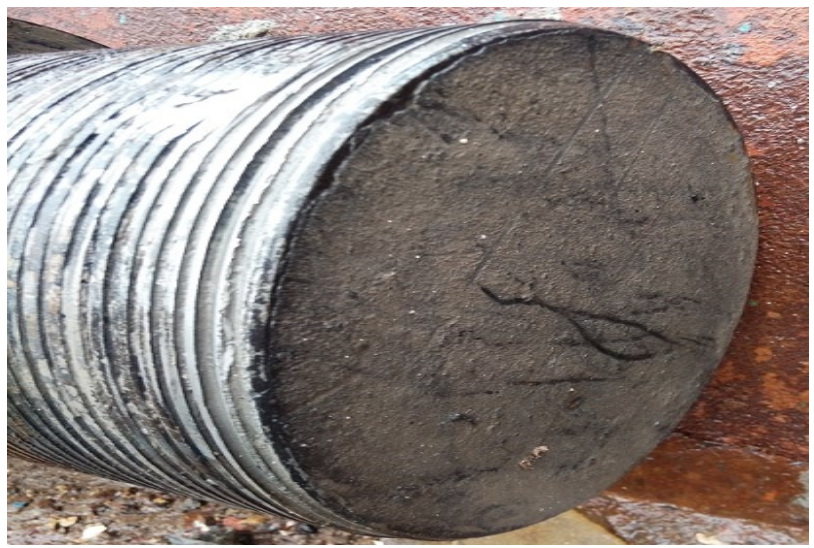

Fig.4 Rudder Stock Bottom

(3) The rudder system was maintained during the last special survey. The maintenance items of the "repair list of the rudder system" are as follows: During the docking repair, rudder cover plates are cut off and welded up; rudder stocks and bearing sleeves are inspected with clearance measured; rudder blade is disassembled and packing glands replaced; safety components of rudder stock nuts $(\varphi 500 \times 300)$ are welded onto the rudder blade (drawing of the nuts safety component is not available, and they are installed temporarily on the spot for safety), rudder blade is not replaced or overhauled; rudder blade reassembling process is supervised by the surveyor, engineering superintendent, chief engineer and chief officer. In accordance with the repair in the shipyard, nuts safety components are fitted on the basis of original rudder blade, which is superior to former one in terms of safety.

\section{Analysis on Causes of Accident}

According to the above investigation and evidence-collection as well as analysis of technical personnel on the spot, the causes that rudder blade lost are as follows:

\section{Analysis on External Cause}

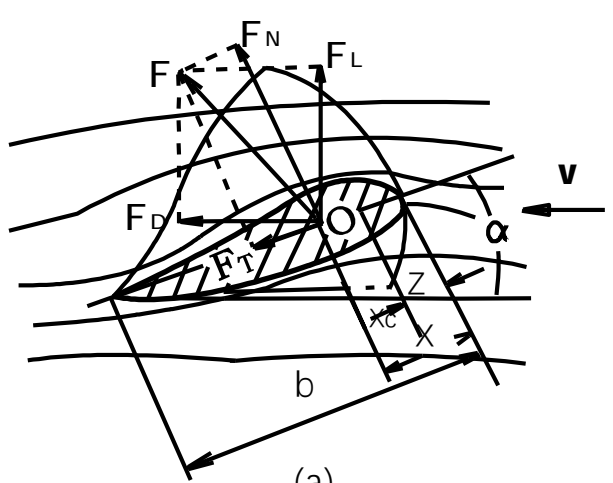

(a)

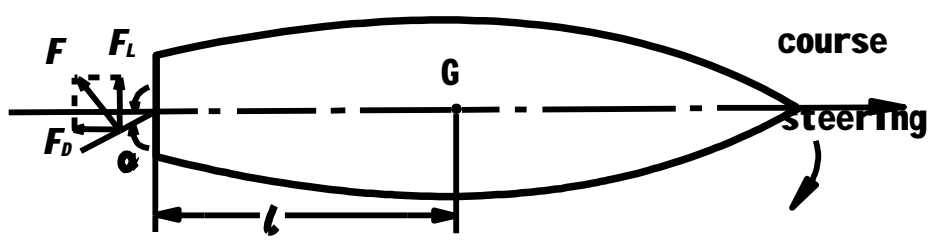

(b)

Fig 5 Water Force to the Rudder \& Effect on the Ship 
As shown in Fig.5, when the rudder blade diverted to a certain rudder angle $\alpha$, the resultant force of the water pressure acted on the rudder blade is expressed by $F_{N}$, and the friction $F_{T}$ which is consistent with the rudder blade center line occurred between the water stream and the rudder blade. The total force of the water is $\mathrm{F}$ which is the resultant force between $\mathrm{F}_{\mathrm{N}}$ and $\mathrm{F}_{\mathrm{T}}$. The water force $\mathrm{F}$ can also be decomposed into a lift $\mathrm{F}_{\mathrm{L}}$ which is perpendicular to the direction of the water flow and a resistance $F_{D}$ which is parallel to the direction of the water flow.

The torque developed by the water force $F$ of the rudder and the center of gravity $G$ of the rudder is called the moment of turning ship, which is represented by $\mathrm{M}_{\mathrm{S}}$. Because the moment arm of force between $F_{D}$ and the ship's center of gravity $G$ is small, the moment of turning ship can be expressed approximately as

$$
M S \approx F_{L} \bullet l=\frac{1}{2} C_{L} \rho A v^{2} l
$$

$\mathrm{Nm}$

In this formula: $\mathrm{C}_{\mathrm{L}}$ - lift coefficient; $\rho$-water density, $\mathrm{Kg} / \mathrm{m}^{3} \mathrm{~A}$-rudder blade area; $\mathrm{V}$ - water velocity at the rudder blade, $\mathrm{m} / \mathrm{s}$; L-distance between center of rudder pressure and center of gravity, $\mathrm{m}$.

The hydrodynamic moment of the rudder is the torque of water pressure $F_{N}$ acted on rudder opposite to the rudder stock axis, denoted by Ma.

$$
M a=F_{N} \bullet \chi_{C}=\frac{1}{2} C_{N} \rho A v^{2} \chi_{C}
$$

$\mathrm{Nm}$

In this Formula: $\mathrm{X}_{\mathrm{C}^{-}}$-the distance between the pressure center of the rudder and the axis of the rudder stock, $\mathrm{m} ; \mathrm{C}_{\mathrm{N}} 、 \mathrm{C}_{\mathrm{X}}$--the pressure coefficient and pressure center of the rudder blade; b--the average width of the rudder blade, $\mathrm{m} ; \mathrm{Z}$ - the distance between the axis of rudder stock and edge of the rudder blade, $\mathrm{m}$.

The water area of the incident is located at a distance of $3 \mathrm{n}$ miles from the nearest land. The sea is vast with depth 177 meters. The wind over the sea is northeastern with grade 4, so as to the wave, and the ocean current is about 3 knots to the south. There are no obstacles such as sunken ships, islands or reefs at the fairway. The navigation and weather conditions are normal. According to the analysis of stress, the speed and current at the time of the incident is slow, that is, the water velocity $\mathrm{V}$ at the rudder blade is not fast. When the ship turns the rudder, the required moment of turning ship MS and consequently the hydrodynamic moment is small. Therefore, the total force $\mathrm{F}$ of acted on the rudder blade and the stress of the rudder stock are also not large enough to cause damage to the rudder blade. Because none of hazardous situations such as collision, ground or rough sea occurred previously, the external cause to lose the rudder blade could also be eliminated.

\section{Analysis on the Reason of Design}

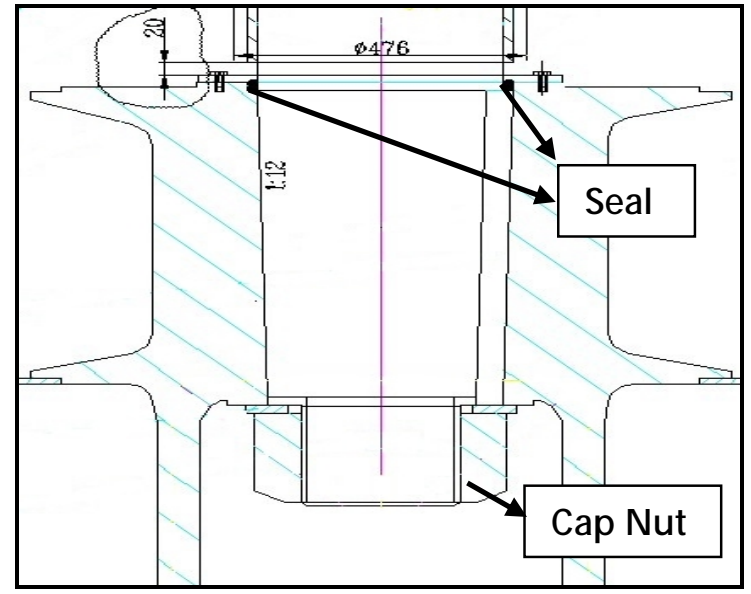

Fig.6 Sealing and Tightening of Rudder Blade

In accordance with referring to the drawings of the rudder blade, it is found that no interlock device fitted between the blade and the tightening nut of the stock. Only one $\varphi 440 \times \varphi 270 \times 16 \mathrm{~mm}$ 
shim made from No. 35 steel is shown in the design drawing. If there is a problem with the gasket, the pre-tightening force of the rudder stock nut may be insufficient and loose consequently. As a result of its own weight, relative motion could happen among the rudder post, blade and the nut (Figure 6).

\section{Failure of Sealing Leads to Leakage of Seawater with Resultant Corrosion and Rudder Blade Loosening}

According to the investigation to the corrosion on the cone surface of the rudder blade as well as drawings and analysis to the repair during special survey, we could suspect that leakage into the lower chamber along the keyway and "trachoma" which is caused by the bad sealing effect between rudder stock and rudder blade (sealing device shown in Figure 6) or inferior sealing quality of the cover plate during welding operation. Both of rudder stocks and gaskets are made of 35 steel and the hardness is HB150 185. Once leaked into the seawater, the gasket will be corroded firstly. As the shim continues to corrode, the pre-tightening force of the rudder stock nut decreases; meanwhile, the break of rudder stock nut and threads also corrode to different extent. Because the nut safety device is welded on the rudder blade leading to the breaking effect of the rudder nut safety device reduced, the nut is subject to great variable friction as the rudder blade rotates to port side and starboard side. When the rudder blade rotates to port side, the rudder stock nut is forced to disengage and the rudder stock nut cannot be tightened when rotating to the starboard side, so the lock nut loosens gradually. When the rudder stock lock nut is retracted to a certain position, the nut is damaged instantaneously by 7 to 8 tons gravity force of rudder blade, resulting in drooping-off of the rudder blade. In a word, the cause leading to loss of the rudder blade is more complex and involves various aspects: the rudder stock nut is lack of breaking device at the design stage; sealing effect of the unit deteriorates or welding quality of the cover plate is inferior; meanwhile, seawater may flow into the nut chamber to lead to corrosion as this part is below the waterline permanently, so the pre-tightening force of the nut could decrease. As various factors exist together, the nut loses fastening effect correspondingly, which is the main cause of this incident.

\section{Conclusions}

According to the analysis on the failure of the hydraulic steering gear, we should do following precautions to prevent such accidents from occurring:

(1) During the process of design, site selection and manufacturing, the steering gear should be paid attention thoroughly by professional and technical personnel. The fix between nut and gasket should be thickened, and the nut breaking device be fitted as well. Meanwhile, the installed rudder blade should be tested for defection or sealing if applicable.

(2) Inspections to the watch-keeping should be enhanced. During the routine inspection and maintenance, the common methods should be taken to detect the defections and faults properly and appropriate repair measures should be made as soon as possible.

(3) Control to the quality of working skills and critical equipments should be strengthened during ship repairing period. Measures should be taken to the management of abnormal process and spare parts which is related to the quality of equipment. Inspections should be made to the rudder blade, rudder stock nut and gasket thoroughly, and reliability of the breaking device should be confirmed.

\section{References}

[1]ZHENG Zhi-guo, LI Cheng-fu. The Measures of Steering Gear Failure. Journal of Qingdao Ocean Shipping Mariners College,2014,35(4):5-7.

[2]HE Fa-ming. Failure Analysis and Improvement on the Steering Gear Hydraulic System of a Ship. Chinese Hydraulics \& Pneumatics,2014,(2):109-111.

[3]LUO Zhi-ming, LIANG Si-yuan. Debugging and Malfunction Analysis for Steering Gear System of Large Vessel. Marine Technology,2016,330(2):83-89.

[4]HOU Chengguang,YUAN Zhaohui, HE Changji.Reliability Analysis of Electro-hydralic Actuator Based on Fuzzy Fault. Machine blade Tool and Hydraulics,2007,35(6):226-227. 
[5]WANG Jin-xiang, YAN Zhong-ping. Dicussion on Fault Diagnosis from a Case of Steering Gear Fault .Marine Technology,2011,(1):55-57. 